\title{
Arte, religión, filosofia. La doble posible interpretación del Espíritu Absoluto en G. W. F. Hegel
}

\author{
Art, religion, philosophy. \\ The double possibility of interpretation \\ of the absolute spirit in G.W.F. Hegel
}

\author{
JAVIER HERNÁNDEZ-PACHECO \\ Universidad de Sevilla \\ Recibido: 25/06/2017 Aceptado: 19/06/2017
}

\section{RESUMEN}

Arte, religión y filosofía son los tres momentos en la reflexión final en sí mismo del Espíritu Absoluto. La cuestión es si se desarrollan de tal modo que cada uno sustituye al anterior de una forma negativa y deconstructiva presidida al final por una filosofía crítica, o si todos no incluyen más bien la referencia intrínseca a los otros dos, en un movimiento dialéctico en el que el Espíritu no puede cancelar en esa triple co-implicación su respectiva diversidad. La referencia a lo que Kant llama «ideal de la razón» y a la triplicidad en la primera filosofía Jónica de physis, logos y arkhé, ayuda a clarificar este problema hegeliano.

\section{PALABRAS CLAVE}

HEGEL; ESPÍRITU ABSOLUTO; ARTE; RELIGIÓN; FILOSOFÍA

ABSTRACT

Art, religion and philosophy, are the three moments in de final reflection of the Absolute Spirit unto itself. The question is whether they develop in such a way that each substitute the former one in a negative and deconstructive way finally presided by a critical philosophy; or whether they all rather include the intrinsic reference to the two other ones, in a dialectical mouvement in which the Spirit cannot cancel in that triple co-implication their respective diversity. The reference to what Kant calls «ideal of reason» and to the Milesian triplicity of physis, logos and arkhé, helps to clarify this Hegelian problem.

\section{KEYWORDS}

HEGEL; ABSOLUTE SPIRIT; ART; RELIGION; PHILOSOPHY 
La FILOSOFía ComienZa en EL SIGLo VI, en la Jonia griega, con el intento de articular un discurso o logos que abarque nuestra experiencia de la naturaleza y desvele su sentido, lógico decimos, remitiendo su pluralidad a la unidad de un arkhé o principio. Ese desvelamiento totaliza la citada experiencia, trascendiéndola en una diferencia onto-lógica, por la que lo limitado se entiende desde lo infinito, lo determinado desde lo inabarcable, lo medido desde lo inmenso, lo definido por un peras, desde el principio que Anaximandro denomina Ápeiron y que Sócrates buscará como origen de las definiciones.

El intento de Aristóteles de restringir esta principialidad de los Milesios a lo que él entiende como materia — con la no muy noble pretensión de salvar su propia originalidad- es probablemente el mayor fiasco hermenéutico de la historia de la filosofía; de la que se hacen cómplices entusiastas los más recientes estudiosos - Burnet, Guthrie, Kirk y Raven, por ejemplo- en su ideológico intento de elevar el materialismo a capítulo primero de esa historia del pensamiento. Lo que en mi opinión es un monstruoso atropello.

Habrá que esperar a la recepción idealista de la filosofía kantiana para entender que aquello que es condición de posibilidad de la experiencia, es, dice Kant, por definición, al trascender toda condición y determinación empírica (eso significa «trascendental»), lo «Incondicionado». En general se nos escapa la clave etimológica que revela la intención kantiana. Be-ding- $t$, lo sometido a condiciones (Be-ding-ungen), es lo que es Ding, cosa. Por el contrario lo que condiciona y de donde procede la citada determinación es das Un-be-ding-te. Lo que deberíamos traducir, además de con el anodino y pedante «Incondicionado» castellano, como «lo que no es cosa». Todas las cosas se entienden, revelan su sentido, desde algo que por definición ya no es una cosa; y eso es el Ápeiron. De ahí pasó la onto-logía, el discurso totalizador sobre lo que existe, que empezó siendo physio-logía y que luego se conocerá como meta-física, a ser filosofía del espíritu. El espíritu revela el sentido lógico de las cosas de las que tenemos experiencia, su última significación, desde sí, desde un absoluto que es actividad pura a priori, causa de sí mismo, y que se sitúa más allá de toda experiencia determinada.

$Y$ eso que al final afirman los idealistas post-kantianos, es exactamente lo que, después de Anaximandro, había dicho ya Anaxímenes. Su aportación nada tiene que ver con una recaída en la cosificación principial, que dicen los manuales, como si situase el origen y sentido de la naturaleza en una mezcla gaseosa de oxígeno, nitrógeno, vapor de agua y dióxido de carbono, que es lo que hoy entendemos por aire. Más bien, lo que verdaderamente dice el de Mileto es que el principio, el mismo que su maestro había denominado Ápeiron como aquello de dónde todo procede y a lo que todo vuelve, abarca y conforta - periekhein y synkratein, son los verbos que emplea el texto de Aecio que nos transmite la tesis central de Anaxímenes- todas las cosas, las 
determina; del mismo modo como el alma da vida al cuerpo, continúa Aecio. No hace falta un exceso de filología para afirmar que si la «pneumática» de Anaxímenes tiene un sentido materialista, entonces tendríamos que conceder un interés meteorológico, en el sentido del hombre del tiempo, a los Hechos de los Apostoles, cuando describen que el Colegio Apostólico recibió al Espíritu Santo en la forma de un "viento impetuoso»; o habríamos de suponer aviesas intenciones de dopaje bioquímico al entrenador de un equipo ciclista que «infunde» ánimo, que es espíritu de victoria, sýnkratos, a su plantilla.

Por eso podemos decir, bien al contrario, que ya en su origen milesio la filosofía era «Fenomenología del Espíritu».

$$
* * *
$$

Naturalmente, dos mil trescientos años después, Hegel expresa esa misma idea de forma mucho más articulada conceptualmente, lo que no quiere decir que con mucha mayor claridad.

La naturaleza, y tras de ella la historia, constituyen para él la manifestación y desarrollo del Espíritu en sus determinaciones concretas; de modo que una descripción de lo que existe y sucede como aquello de lo que tenemos experiencia, una fenomenología pues, es a la vez «historia de la experiencia de la conciencia». A través de esa experiencia, que lo es por igual de las cosas y de sí misma, la conciencia se eleva a autoconciencia, reconociéndose en sus contenidos fenoménicos. Y ocurre así que esa descripción de la naturaleza y de la historia es igualmente verdadera fenomenología del Espíritu, como camino por el que éste llega al conocimiento de su última verdad. A saber, que es Espíritu Absoluto, allí donde se hace, en expresión paulina, Todo en todas las cosas. De este modo, como Absoluto, el Espíritu es auto-determinación y auto-revelación, en la reflexión última en que todas las cosas son también verdad o manifestación de sí mismas en la totalidad de sentido que por medio de ellas se hace concreto y a la vez saber absoluto de dicho Absoluto.

Es posible que esto no se entienda mucho. Pero quizás por eso no estemos descaminados, porque el Absoluto es resultado y aparece como tal sólo al final. Así que intentaremos seguir avanzando en espiral, por un camino en el que la profundidad aspira a ser luminosa claridad en el cierre de la reflexión.

Eso que Hegel llama Espíritu Absoluto se diferencia del espíritu subjetivo, que es la autoconciencia distinta que tenemos de nosotros mismos como individuos frente a un mundo. También del espíritu objetivo, que es la red de estructuras históricas e institucionales que mediatizan esa conciencia de nosotros mismos y que hacen de la reflexión un camino de vuelta en sí desde la objetividad cultural, económica y social. El Espíritu Absoluto es el término de ese camino al final del cual el Yo es, no un sujeto particular, sino el momento reflexivo que cierra y concluye la historia como el sujeto, encarnación del todo 
sujeto posible, que la comprende comprendiéndose a sí mismo en ella. Haciendo una peligrosa abreviatura podríamos decir que el Espíritu Absoluto es el Dios que reconoce en todas las cosas los momentos particulares de su propio devenir. Tampoco es que esto se entienda fácilmente. Así que pasaremos a describir la estructura de ese Absoluto en lo que Hegel dice que son los tres momentos de esa subjetividad total. Como sabemos son el arte, la religión y la filosofía.

Podríamos decir que el arte es el Absoluto difuso en su aparecer, en su fenomenidad; es el Absoluto puesto por obra. Si queremos, es la materialización, o manifestación sensible, de ese Espíritu. De modo que su característica propia es la belleza, que es, dice Hegel siguiendo a Platón, manifestación sensible de la Idea. Pensemos, por ejemplo, en el Doríforo de Policleto. ¿Es sólo un chaval haciendo ejercicios militares con la lanza? Es mucho más; es, y en eso consiste su belleza, manifestación de un ideal de humanidad. Y como tal es el canon o medida, lo inmenso o arquetípico, el paradigma que define lo que todos físicamente aspiramos a ser o lamentamos no haber sido. Pero entonces es más que un hombre, es imagen de lo perfecto, y por tanto presencia adecuada de lo divino.

San Pablo, cuando llegó a Atenas, se escandalizó, cuentan los Hechos de los Apóstoles, al ver la ciudad llena de ídolos. Pero ahí se equivocaba el de Tarso. Porque la idolatría es la cosificación del Absoluto; mientras que la plástica griega lo que hace es presentar en los cuerpos y sin confundirlo con ellos lo que en la materia supera esa corporalidad. Más bien entonces, capta lo que es en las cosas su referencia constitutiva a lo que esencialmente las trasciende. No es un descenso de lo absoluto, sino una ascendente absolutización de lo que quiere ser perfecto. No son las piedras, o temibles y horrorosos animales, los que se presentan como sagrados, sino el hombre o la mujer en la dimensión trascendente en que la belleza de sus cuerpos se hace, de algún misterioso y a la vez patente modo, presencia de Dios.

Podríamos decir que el arte capta lo absoluto, lo perfecto y divino, como adjetivo en las cosas, como aquello que en ellas remite a su principio y perfección. Ahora bien, por lo mismo el arte entra por así decir en conflicto consigo misma; o capta eso absoluto en la contradicción de su relatividad sensible. Buscando lo adorable en las cosas, lo divino como adjetivo en ellas, se da cuenta de que necesariamente fracasa en su intento, porque anhela algo que las cosas no pueden dar en su particularidad. Y de ahí la tendencia de toda poesía - Hegel sigue aquí de cerca a los románticos de Jena— a hacerse oración, buscando lo inefable más allá de sí misma. La religión, que es reconocimiento del Absoluto, de lo divino, no en su dispersión material y adjetiva, sino en sí mismo como sustantivo, guarda entonces la verdad del arte. Y se convierte en reverente adoración de un Espíritu que se muestra como tal en su trascendencia: al Señor, tu Dios, adorarás y a Él sólo servirás, nos dice la Escritura. 
Dios es así la perfección y verdad de todas las cosas, como lo esencialmente distinto de todas ellas. Es el Absoluto en la forma de sujeto, de un Yo, que en esa trascendencia es lo absolutamente Otro. Y entonces también un Tú extraño.

En ese paso a la trascendencia, la relación de la religión con el arte no puede ser sino conflictiva. Mientras que el arte se enamora de las cosas, la religión percibe como pecado esa conversio ad creaturas en que termina el esteticismo. Y requiere entonces la exclusividad de un amor que se convierte en celoso comtemptus mundi, que es desprecio de las cosas y en último término de nosotros mismos. Nos las habemos aquí con el momento destructivo e iconoclasta de un monoteísmo que pretende salvaguardar su pureza por ejemplo en la dramática exigencia del sacrificio de Isaac.

Pero no podemos ir muy lejos por ese camino sin darnos cuenta de que la religión pasa de la contradicción de un Absoluto adjetivo que veíamos en el arte, a la de un Sujeto que es igualmente contradictorio como lo absolutamente Otro, que resulta ser negación de toda subjetividad. Dios es el Yo que por principio no soy yo; la contradicción de mí mismo: yo mismo en la forma de la alienación. Dios no tiene otro contenido que mi propia autoconciencia puesta fuera de sí, a salvo eso sí, de su negatividad corporal y sensible; a salvo en último término de la muerte que amenaza como corrupción a todo lo que se genera.

Ahora bien, entender esto es, por lo mismo, recuperar la propia autoconciencia. Recuperación que tiene ahora la forma de una crítica de la religión que se hace filosofía, y en la que por fin, en la idea de Dios como proyección de sí mismo, el sujeto cierra reflexivamente la historia de su propia experiencia como conciencia; reflexión que es reconocimiento de sí en la fenomenidad natural. En esta idea de sí mismo que rescata reflexivamente de la alteridad divina, el espíritu se realiza definitivamente como Absoluto.

$* * *$

Hasta aquí se trata de un repaso del Manual. Lo importante es dilucidar ahora la relación que esos tres momentos del espíritu Absoluto: arte, religión y filosofía, tienen entre sí. Porque creo que en el modo de entender esa relación está la clave, para una definitiva interpretación de la filosofía de Hegel, y siendo como ésta es una recapitulación de nuestra historia occidental, también para la comprensión de nosotros mismos.

La narración conceptual que provisionalmente hemos hecho sugiere primariamente una sucesión lineal de los tres momentos, de modo que en esa sucesión cada uno sustituye al anterior. El arte, en su insuficiencia, daría así paso a una visión religiosa del mundo, que en su carácter contradictorio desembocaría, a su vez, en una filosofía cuya última misión sería criticar la pretensión de las otras dos, de arte y religión, de constituirse ellas mismas en Absoluto. Ya sea como crítica de las ideologías, como desmontaje psicoanalí- 
tico o como deconstrucción de su génesis a partir de la voluntad de poder, la filosofía, extendiendo su sospecha sobre toda supuesta trascendencia espiritual, terminaría así en una absolutización de la relatividad, en cualquiera de las formas de materialismo, culturalismo, simbolismo lingüístico, psicologismo, a que nos ha acostumbrado el pensamiento contemporáneo como deconstrucción de lo que quería ser fenomenología del espíritu. Así, tendríamos que reconocer a la izquierda hegeliana los derechos de albacea sobre la herencia del idealismo, cuyo ejercicio ha terminado en la descomposición post-moderna de lo que parecía ser subjetivismo absoluto.

Y la cuestión es: ¿es ésta la única interpretación posible del pensamiento hegeliano?; ¿es la más respetuosa con su original inspiración? La pregunta es menos retórica de lo que a primera vista podría parecer. Digamos que no me creo capaz de sacar de la chistera hermenéutica un conejo especulativo que haga ahora de toda la filosofía dialéctica punto de apoyo para la restauración del espiritualismo filosófico con el que yo estoy intelectual y vitalmente comprometido. Pese a lo cual, y asumiendo los límites subjetivos de toda interpretación, lo voy a intentar, dejando a la buena voluntad de auditorio juzgar sobre la viabilidad de la pirueta conceptual.

La interpretación izquierdista de Hegel depende a su vez del alcance especulativo del verbo aufheben. Porque es claro - es un tópico de manual- que cada momento del Espíritu Absoluto hebt auf al anterior. ¿Y cómo traducimos eso? Es importante esta traducción, porque la izquierda hegeliana ha cobrado fuerza en no pequeña medida mediante su difusión en ámbitos lingüísticos distintos del alemán. Por ejemplo en Francia, y por supuesto en nuestra propia tradición española y latina. ¿Podemos decir entonces que la religión «supera» al arte, y en su conclusión la filosofía «deja atrás» a las otras dos formas del Absoluto? ¿Y qué significa «superar»?, ¿comprender, sustituir, y al final deconstruir, en un proceso al término del cual la filosofía asiste solitaria al definitivo Viernes Santo especulativo en que el Absoluto se disuelve en reflexión crítica?

Creo que apelando a la semántica del término alemán, piso firme terreno para decir que esa traducción es cuando menos apresurada. Aufheben, como todos sabemos, significa «quitar de en medio», pero en absoluto «dejar de lado» y mucho menos «atrás». Es también en cierto sentido «limpiar», pero no para «tirar a la basura». Se trata más bien de «poner las cosas en su sitio», de «ordenar». Y su resultado sería algo así como «guardar» y «conservar». Algo muy distinto a lo que entendíamos la generación sesentayochista, todos hegelianos de izquierda, cuando mirando despectivamente a nuestros mayores les decíamos aquello de «tú estás superado». Así entendíamos el momento psicoanalítico de «matar al padre» en absoluto como transición sino como aurora definitiva de la emancipación personal e histórica. 
Pero pienso, al contrario, que la consecuencia de este paseo filológico es que arte, religión y filosofía, los tres momentos del Espíritu Absoluto, lejos de sustituirse en una sucesión lineal, se integran en un proceso a cuyo término cada uno de ellos conserva su vigencia en la totalidad reflexiva en la que quedan al final coimplicados, algo así como vértices respectivamente abiertos de un triángulo; de modo que cada uno de ellos tiene la verdad en los otros dos, y son por eso tales momentos del Absoluto. Por lo mismo, desconectados unos de otros, cada uno pierde, por así decir, su propia esencia; se desvirtúa y pervierte.

Detengámonos un momento en lo que sería una fenomenología de la citada perversión. Pensemos en el arte: en sí misma, desconectada de la filosofía y de la religión, deviene en esteticismo, en el que el Absoluto que representa decae en pura sensibilidad. Sin religión, que quiere decir, sin referencia al Absoluto que la trasciende, el arte pierde su carácter de signo y símbolo, y se vacía en pura sensación. Algo así, en el extremo, como el que haciendo profesión de ateísmo pone los ojos en blanco y cara de trance escuchando La pasión según San Mateo. Y da igual si no sabe alemán, porque lo que dice se ha hecho irrelevante. De igual modo, sin filosofía el arte renuncia a la significación en la que tiene sentido, y se vacía de él en lo absurdo. Es el camino que siguen las vanguardias, en la que todo discurso estético se disuelve en académicas reflexiones sobre el orinal de Duchamp, la cucaracha de Kafka o el cuadrangular colorido de Mondrian. Reflexiones que carecen de sentido, porque son ganas de buscar lógica allí donde ésta se desprecia.

Más trágico es, en esa triple desconexión, el destino de la religión. Convertida para ella el Absoluto en lo extraño, en lo absolutamente Otro, la religión sin filosofía se hace gnosis fideista que renuncia a todo argumento y se alimenta de la irracional adhesión sectaria, igualmente carente de todo sentido que pudiéramos reconocer desde nuestra naturaleza corporal y sensible. Y así sin arte, hecha furia iconoclasta, la religión se hace fanatismo, enemiga del mundo, y exige de una naturaleza igualmente vaciada de sentido un aniquilador holocausto. Devaluada a inane toda subjetividad que no sea la divina, el otro corporal, convertido en cosa, queda igualmente aniquilado. Imposible de reconocerlo en el prójimo al que vemos, el Dios que no vemos se hace enemigo de la humanidad, pretexto de toda misantropía, hasta que termina siendo el último arquetipo del nihilismo. De Él dice Nietzsche: los cristianos - y valdría para toda religión que abomina de la estética y la representación- no lo saben, pero adoran a un Dios muerto.

Por último, la filosofía, a la que se encomienda el desmontaje crítico de toda significación, queriendo saber, acaba en escepticismo nominalista. Sin arte, se hace tautología analítica obsesionada con la consistencia del discurso; y sin religión, como señala Horkheimer, pura constatación del poder último 
de los hechos, consagración de lo que hay, como reducto vacío e inerte de lo que antes era naturaleza y afán de ser.

Cualquier intento de reconocer en este triple divorcio lo que en algún momento Hegel quiso llamar Espíritu, condena en mi opinión al fracaso a la hermenéutica que quisiera ser respectiva exclusión de esos tres momentos de lo absoluto. Y nos obliga a asumir la sentencia de Adorno de que el Sistema no sería sino la totalidad de lo falso. La filosofía de Hegel terminaría así en la contradicción de sí misma. (Lo que quizás no sea una mala conclusión dialéctica.)

Pero dejemos aquí nuestra digresión, que intentaremos recuperar después, no sin antes dar un rodeo por ese oscuro pasaje de Crítica de la Razón Pura en que Kant habla del «Ideal de la Razón». Tiene que ver, como es sabido, con las ideas trascendentales mediante las que la razón totaliza, en busca de lo incondicionado, las condiciones de la experiencia externa (en la idea de mundo), de la experiencia interna o subjetiva (en la idea de alma) y de todo lo pensable en absoluto (en la idea de Dios). Es sabido, por un lado, que estos conceptos de la razón trascienden los límites de dicha experiencia y se quedan, por así decir, sin intuición que subsumir bajo ellos; por lo que, a diferencia de las categorías del entendimiento, no constituyen objetos que pudiesen ser descritos con una validez a priori al modo de las ciencias naturales. Pero ello no quiere decir que sean «meras ideas» o elucubraciones; pues son formas necesarias que actúan regulativamente, a saber, como reglas para la estructuración del conocimiento en general, que no se detiene en los límites finitos, sensibles por tanto, de la experiencia posible.

Kant no insiste mucho en ello, pero es evidente en su sistema que esta tendencia a trascender el límite de su finitud, tiene que ver con la actividad pura a priori que está como un «Yo pienso en absoluto» en el origen de toda la actividad sintética del sujeto; actividad pura, de algún modo infinita, que buscando reconocerse a sí misma en sus contenidos, impone las condiciones de su síntesis desde un límite incondicionado, que es siempre respecto de esos contenidos un «más allá»; un Ápeiron, por tanto. Trascendentalidad, que es lo que afecta a las condiciones del conocimiento en tanto tal, tiene que ver con trascendencia. No en el sentido de un «fuera» de la experiencia - pues ya sabemos que no hay objetos con independencia de ella-, sino precisamente de una interioridad subjetiva que como actividad trasciende aquello que en cada caso determina.

Es por ello que todo el conocimiento tiene, por así decir, vocación de infinitud; es siempre un plus ultra. Y abre así, hacia fuera, el horizonte de un mundo que enmarca toda experiencia, y hacia dentro, la profundidad de un alma que busca, precisamente en el mundo, reconocerse a sí misma. Por lo mismo, 
esas dos ideas trascendentales tienden por su propia naturaleza dinámica a confluir. Ciertamente en un límite infinito, inalcanzable en el marco finito y condicionado de la experiencia, pero igualmente irrenunciable. El sujeto quiere conocer todo, del todo; y en todo reconocerse totalmente a sí mismo.

Pues bien, ese límite inalcanzable, eso incondicionado último que es origen de todas las condiciones que estructuran las cosas como objetos; ese límite focal, esencia y arquetipo de toda realidad e idealidad; límite en el que alma y mundo serían lo mismo, es lo que Kant llama «ideal de la razón pura», tradicionalmente designado con el nombre de Dios. No es propiamente una tercera idea trascendental, sino efectivamente el ideal de la síntesis de las otras dos, exigido por una razón que consiste precisamente en buscar su límite incondicionado. Sería algo así como el vértice superior de un triángulo hacía el que tendencialmente confluye, como a su origen, principio y fundamento trascendente y trascendental a la vez, real e ideal- esa actividad de la razón; confluye, digo, desde los otros dos vértices - experiencia externa e interna, objeto y sujeto, naturaleza y logos - que constituyen como punto de partida la base por así decir finita del citado triángulo.

No es difícil reconocer en esta triangularidad kantiana de las ideas trascendentales el mismo esquema dinámico que al principio vimos en el origen jonio de la filosofía como physis, logos y arkhé, a los que en el lenguaje escolástico que Kant recoge de Wolff corresponden efectivamente el mundo, el alma y Dios. Correspondencia, por otra parte, que sirve para recordarnos que el límite infinito, trascendente y trascendental a la vez, de lo que, insisto, más que figura geométrica es un proceso dinámico de síntesis; el arkhé pues que es Dios, es al mismo tiempo Ápeiron: lo que limita sin ser limitado, la actividad que condiciona desde su absoluta incondicionalidad. Y es por tanto lo que desde su diferencia ontológica, desde su — perdón por el palabro- «másallaeidad», es, frente a las cosas (Dinge) en su limitado y condicionado ser, y frente a las limitadas e igualmente condicionadas representaciones que nos hacemos de ellas, es, repito, el Espíritu (Unbedingtes), como lo que conoce del todo todo lo que es y en todo se reconoce del todo a sí mismo.

$$
* * *
$$

Recordemos que esto era un rodeo en nuestra digresión, en la que habíamos dejado sin resolver la posible interpretación en Hegel de la relación interna entre los tres momentos del Espíritu Absoluto que son arte, religión y filosofía. Pretenso sostener que, mutatis mutandis, la triangularidad physis, logos, arkhé, que hemos visto se corresponde con la kantiana de mundo, alma y Dios, con cierta holgura la podemos reconocer ahora en los tres momentos hegelianos del espíritu absoluto: el arte correspondería así a la presencia en el mundo de su principio ideal y absoluto; principio que en forma de filosofía 
recoge reflexivamente el alma en sí misma; y la religión, dejémoslo de momento en su máxima ambigüedad, tiene que ver con el reconocimiento de Dios como sujeto absoluto. Arte, religión y filosofía, serían así el trípode hegeliano que reproduce la citada triangularidad jonia y kantiana. No ahora como instancias que se sustituyen linealmente, sino como una triple dimensión de lo mismo, del Absoluto: hacia fuera en las cosas, como arte; en sí mismo como término de la adoración, en la religión; y como reconciliación de ambas tendencias, alienante una y reflexiva la otra, en la filosofía.

Si consideramos en su respectiva apertura esos tres momentos, la interpretación que cabe hacer del sistema hegeliano es muy diferente a la que resultaba de su continuación por la izquierda. Un arte abierto a la religión, sin pretender ser inmediata presencia de Dios que sería imposible en la exterioridad material, fuera por tanto de toda beatería mística, resulta así desde su constitutiva insuficiencia mundanal referencia a una trascendencia tan indisponible como necesaria, anhelo de un ideal que supera a cada una de sus obras. No otra cosa es lo que Platón llamaba el eros, que liga a las cosas con el bien a través de la belleza. Mas por lo mismo, un arte así entendido, percibiendo lo absoluto en su fragmentariedad material, en nada renuncia a su sentido lógico; es más se convierte como poesía, justo asumiendo como metáfora su fractura semántica, en vehículo de expresión de lo inefable. Por lo mismo, en su apertura ahora descendente hacia lo finito en que se manifiesta lo absoluto, la religión, lejos de ser desprecio del mundo y de la vida y adoración nihilista de lo absolutamente otro, es, justo al contrario, reconocimiento, ahora explícito, de eso absoluto que se encarna en las cosas, en la misma corporalidad del mundo; y es así buena voluntad, Evangelio, Buena Noticia, que como misericordia acoge el eros en que toda realidad consiste. E igualmente, abierta a la filosofía, es esa religión renuncia a todo fanatismo, en el reconocimiento de que el Absoluto que ella venera ha de ser el mismo que como principio de todas las cosas es accesible en el mundo para todo sujeto posible; de modo que lo que ella adora es a la vez objeto de una discusión crítica que somete toda veneración a las reglas compartidas de la lógica.

Hemos de preguntarnos para ir concluyendo: ¿cabría interpretar a Hegel en este sentido, a mi modo de ver más amable; sobre todo más cercano a la tradición filosófica de Platón, Aristóteles, por supuesto de la filosofía cristiana; y muy especialmente en conformidad con lo que fue en las mismas calles que él piso poco después, la recepción que hacen los jóvenes románticos de Jena del criticismo kantiano y del idealismo de Fichte?

La interpretación es libre, y los que me conocen saben de mi liberalidad con los textos a interpretar, que fácilmente, para algunos quizás abusivamente, convierto en expresión de lo que yo mismo quiero pensar. Pero tengo que 
reconocer aquí —ya lo hice antes — que no estoy muy seguro de que Hegel se rindiese a mis alegrías hermenéuticas.

Y no estoy seguro, porque para ello él tendría que firmar la paz con sus inmediatos predecesores románticos, a los que debe tanto, como por otra parte insiste en distanciarse de ellos. En concreto, tendría que rendir la pretensión de que en el cierre reflexivo de su sistema, fuese la filosofía, entendida estrictamente como ciencia, nada menos que como saber absoluto del Absoluto, la instancia que tuviese la última palabra. Del mismo modo como Goethe tendría también que asumir que esa última palabra tampoco la tiene el arte y la poesía. Ambos tendrían que aceptar que una última palabra, como logos o como experiencia estética del mundo, está fuera del alcance de nuestra finitud. En cualquier caso, reconstruir como Fenomenología del Espíritu una Metafísica, que es a la vez ética y filosofía de la historia, more geometrico demonstrata, tentación spinoziana que acecha a todo el sistematismo idealista, ya no es posible.

Por eso me apoyo en Kant, que hace tiempo que en esta discusión estaría, no sé si frenéticamente pero seguro que con energía, agitando banderas rojas. El Ideal de la Razón Pura, que es el lugar que ocupa el Absoluto en la arquitectura de la Crítica, está, como dicen los británicos, out of bounds. No en el sentido wittgensteniano de que estuviese fuera de los límites del mundo, como si ese mundo fuese algo cerrado en sí mismo; o más allá del lenguaje lógico, como algo que nos obligase a callar sobre lo que es el límite incondicionado de sus propias condiciones significativas. Antes bien, ese Ideal es justo el Ápeiron que la razón necesariamente supone en sus mucho más humildes tareas de determinación objetivante; pero justo por ello es aquello de lo que no puede disponer como objeto. Por eso Kant es bien consciente, y avisa de ello, de que ese Ideal de la Razón no es tampoco algo que una filosofía crítica pudiese al final deconstruir como la reflexión que se recupera desde una alienación. Mucho menos es lo que tuviésemos que desenmascarar como lo en sí mismo sospechoso. Ese Ideal es el límite mismo de la diferencia ontológica desde la que somos lo que somos: un yo que piensa, no esto o aquello, sino überhaupt, en absoluto; y que puede por ello acompañar, dándoles sentido lógico, a todas sus representaciones.

Y ahora concluyo yo dejando esto, lo sé, bastante deshilvanado. Porque por esa misma razón — más o menos, como a mí me gusta hablar — arte, religión y filosofía, además de respectivamente abiertas, son irreductibles unas a otras y han de coexistir en su diferencia. Pues el Absoluto sigue siendo para todas, también para la religión, quizás especialmente para la religión, un más allá. Y por lo mismo tienen cada una sus derechos propios. Pensemos por ejemplo en lo insufrible que sería un arte puramente racional para el que todo ornamento fuese delito; o una estética beata para la que lo bello se hiciese fácilmente pecado. Mas por lo mismo, esos derechos propios no son fueros para demarcaciones 
excluyentes. Y así nos recuerda Platón que no hay filosofía que no arranque hacia la idea por el camino de la belleza. Ni tampoco — termino yo - hay saber al que fuera a sobrar un punto de devoción, y algo de ese arrepentimiento de sus audacias que es - a veces lo olvida Hegel — el camino de la reconciliación.

Javier Hernández Pacheco es catedrático de filosofía en la Universidad de Sevilla.

Linea Investigación:

Filosofía clásica alemana, metafísica

Últimas publicaciones:

¿Alguien entiende a Dios? Reflexiones sobre el Catecismo de un profesor de filosofía. Madrid. Sekotia. 2017. 464. ISBN 978-84-16921-22-5

«Erotismo y corporalidad. Reivindicación del sexo salvaje» en Naturaleza y libertad, X. Málaga, 2018.

Email:jpacheco@us.es 